\title{
Optimization of BY2 Cell Suspension as a Stable Transformable System
}

\author{
Zhou SHUMIN ${ }^{a}$, Chu YANXIA ${ }^{\mathrm{b}}$, Zheng BANG, Zhang WEI* \\ Shanghai Key Laboratory of Bio-Energy Crop, the School ofLife Sciences, Shanghai University, China; zhw62207@shu.edu.cn (" ${ }^{*}$ corresponding author); \\ ${ }^{a, b}$ Authors equally contributed to the work
}

\begin{abstract}
Tobacco (Nicotiana tabacum) cv. 'Bright Yellow 2' (BY2) cell suspension is a useful system to study the structure and function of plant cell. However, low efficiency of Agrobacterium-mediated transformation, and transgene silencing during subculture limit its application. Here we present optimization of the traditional protocols of Agrobacterium-mediated transformation and genomic DNA extraction. The transforming efficiency and recovery ratio of genomic DNA extraction were substantially increased by these improvements. Southern assay demonstrated that copy number of transgene could be determined unambiguously. Meanwhile by monitoring the GFP fluorescence we found that the GFP expression can keep stable in suspension culture cells for at least 20 days in liquid medium. Finally, applicability of constitutive promoters of Arabidopsis thaliana UBIQUITINIO (AtUBQ10) and ARABIDOPSIS SKP1 HOMOLOGUE1 (AtASKI) also can drive stable GFP expression in vivo of BY2 cells like CaMV $35 S$ promoter in this plant system.
\end{abstract}

Keywords: transgenic cells, transgene expression, promoter, GFP gene, Nicotiana tabacum BY-2

Abbreviations: $\mathrm{BY} 2=$ Bright Yellow 2; GFP $=$ Green Fluorescence Protein; CaMV 35 S promoter $=$ Cauliflower mosaic virus promoter; AtUBQ10 promoter = Arabidopsis thaliana UBIQUITIN10; AtASK1 promoter $=$ Arabidopsis thaliana ARABIDOPSIS SKP1 HOMOLOGUE1; RT-PCR = Reverse transcriotion-polymerase chain reaction; $\mathrm{CTAB}=$ Hexadecyltrimethy Ammonium Bromide; DAPI = 4,6-Diamino-2-Phenyl Indole

\section{Introduction}

Tobacco (Nicotiana tabacum L.) cv. 'Bright Yellow 2' cell suspension (BY2) has been broadly used in plant cell biology (Duby et al., 2010; Link and Cosgrove, 1998). However, some problems remain and impede application of this system up to date. One prominent issue is low efficiency of Agrobacterium-mediated transformation, and the other problem of transgene silence during subculture makes it worse to use such system to perform experiment in long term (Vaucheret et al., 1998; Ito et al., 1997). For example, in investigating the function of cell cycle genes in BY2, it would be difficult to obtain precise replicable data if the transgene is silenced during subsequent proliferation cycles without an expectable timing.

In addition, the tremendous large BY2 genome (approximately 4.8 billion base pairs) makes it very hard to determine copy number of transgene using traditional DNA gel blotting assay (Southern assay), even such knowledge is necessary for investigating dose-dependent traits. The requirement of adding antibiotics at each subculture in traditional protocols to prevent growth of untransformed cells also imposes toxic effect, severely affecting the fidelity of treatment experiment using plant growth factors or stress stimulation substances (Miao and
Jiang, 2007; Sparkes et al., 2006; Cogoni and Macino, 1999).

Though as a broadly applied constitutive promoter in plant, Cauliflower mosaic virus (CaMV) $35 S$ promoter often fails in driving constitutive expression in early development of male and female reproductive organs and in macro- and microgametophyte (Zhang et al., 2008; Nizampatnam et al., 2009). Recently maize (Zea mays) UBIQUITIN 1 (ZmUBQI) promoter has been used for constitutive expression of genes of several crops (Cornejo $e t$ al., 1993). However, this promoter has been found to be temperature-responsive such that it is limited in certain field studies (Chen et al., 2007). Arabidopsis thaliana UBIQUITIN 10 (AtUBQ10) might be a good substitute of ZmUBQ1 promoter, especially in dicots, since its transcript has been used as a constitutive internal control in quantification of some Arabidopsis temperature-responsive mRNAs (Grefen et al., 2010). Furthermore, the ARABIDOPSIS SKPIHOMOLOGUE1 (AtASKI) gene encodes a homolog of human and yeast Skp1 proteins (Yang et al., 1999) and is essential for many aspects of plant development through ubiquitin-mediated degradation of proteins by proteasomes (Zheng et al., 2002; Sullivan et al., 2003). AtASK1 also had been reported to be expressed 
473

broadly in male and female reproductive organs (Yang et al., 1999; Liu et al., 2004; Wang et al., 2004; Teixeira et al., 2005). However up to date there are few reports about using of either $A t U B Q 10$ or $A t A S K 1$ promoter to drive expression of transgene even in Arabidopsis.

Here we reported that we had tried to optimize the Agrobacterium-mediated BY2 transformation procedure. The adjustment on final liquid medium volume and cell density made it much easier to obtain callus with transgene stably integrated than the traditional method. Meanwhile we optimized the genomic DNA extraction to recover sufficient genomic DNA for performing Southern assay, and characterized GFP expression driven by CaMV $35 S$, AtUBQ1O and AtASKI promoters. We found the transgene could be stably expressed for at least 3 subculture cycles, approximately 20 days in liquid medium. In later stages of subculture, antibiotics could be dismissed so that some stress simulation experiment could be performed without the interference of the adverse effect of antibiotics. The relative constitutive expression efficiency of CaMV 35S, $A t U B Q 10$ and $A t A S K 1$ was quantified and estimated by both fluorescence observation and semi-quantitative RTPCR.

\section{Method and material}

\section{Plant Material}

The original non-transformed tobacco (Nicotiana tabacum L.) cv. 'Bright Yellow 2' (BY2) suspension was cultivated in a modified liquid Murashige and Skoog (MS) medium (4.3 g/L MSO221 sigma, 3\% Sucrose, $0.1 \mathrm{mg} / \mathrm{ml}$ myo-Inositol, $1 \mu \mathrm{g} / \mathrm{ml}$ Thiamine, $0.2 \mu \mathrm{g} / \mathrm{ml}$ 2,4-D, $0.2 \mathrm{mg} / \mathrm{ml}$ $\mathrm{KH}_{2} \mathrm{PO}_{4}, \mathrm{PH}$ 5.8) (Nagata et al., 1992; Link and Cosgrove, 1998; Duby et al., 2010), at $28^{\circ} \mathrm{C}$ with $120 \mathrm{rpm}$ shaking on an orbital shaker in the dark and maintained by weekly dilution $(\mathrm{V} / \mathrm{V}=1 / 20)$ of cell in $100 \mathrm{ml}$ liquid medicine.

\section{Plasmid GFP Expression Construct}

GFP coding sequence was amplified by PCR using the primers as follow: the forward primer GFPF with CACC at its 5' end (5'-CCACATGGTGAGCAAGGGCGAGGA$\left.3^{\prime}\right)$ and the reverse primer GFPR (5'TTACTTGTACAGCTCGTCCA-3'). Approximately 3000bp AtUBQ10 and AtASK1 promoter sequences were amplified using the AtUBQ10 promoter forward primer UBQ10F with CACC at its 5'end (5'CCACATGGTGAGCAAGGGCGAG-3') and the reverse primer UBQ10R (5'-TTACTTGTACAGCTCGTC-3'), the AtASK1 forward primer ASK1F with CACC at its 5 , end (5'-CCACAGAGCATCTAGCTGAGCA-3') and reverse primer ASK1R (5'-AGGGAAATTAGGAAA TTGTTTCA-3'). The amplified GFP CDS, $A t U B Q 10$ and AtASK1 promoter sequences were integrated into the TOPO ENTRY vector (Invitrogen) and confirmed by DNA sequencing. The verified correct GFP-ENTRY construct was recombined with $\mathrm{pGWB} 2$ (Invitrogen) construct to generate 35S:GFP expression vector, while UBQ10-ENTRY and ASK1-ENTRY constructs were recombined with pGWB4 (Invitrogen) to generate AtUBQ10:GFP and AtASK1:GFP expression vectors, respectively.

\section{BY2 Cell Transformation}

The transformation of BY2 suspension was carried out by a modified method described previously (Nakayama et al., 2000; David and Perrot-Rechenmann, 2001). 5ml 3-d-old, exponentially growing suspension of original non-transformed BY2 cell was transferred into a $60-\mathrm{mm}$ culture dish and blown for 20 times, then incubated at $28{ }^{\circ} \mathrm{C}$ with $100 \mu \mathrm{l}$ Agrobacterium GV3101 strain $\left(\mathrm{OD}_{600}=0.6\right)$ harboring transgene expression construct in dark. After $48 \mathrm{~h}$ of cocultivation, the cells were washed with $25 \mathrm{ml}$ modified MS medium only once and plated on a modified MS solid medium containing $25 \mu \mathrm{g} \mathrm{mL}-1$ hygromycin and $100 \mu \mathrm{g} \mathrm{mL}$ vancomycin. After 3 weeks of incubation, the novel hygromycin-resistant calluses were transferred onto fresh solid medium plates containing $25 \mu \mathrm{g} \mathrm{mL}{ }^{-1}$ hygromycin. 2 weeks later, the calluses could be subjected to genotype and phenotype (including transgenic fluorescence) analysis. As for Southern assay, however, more cell proliferation should be committed through inoculating callus in liquid medium for 10 days.

\section{Southern Hybridization Assay}

Exponentially growing transgenic BY2 suspension cells were harvested and extracted by our modified CTAB-based method (Lutz et al., 2011). In detail, BY2 cell was collected from $100 \mathrm{ml}$ 10-day liquid culture by centrifuge ( $5000 \mathrm{rpm}, 15$ minutes). Then the cell pellet was freeze dried at $-40^{\circ} \mathrm{C}$ overnight. The dried cell pellet was ground to powder in liquid nitrogen with help of carborundum. Then the DNA was extracted according to the conventional procedure of $\mathrm{CTAB}$ method.

Southern blot was performed as modified protocol described (Sambrook and Russell, 2001). In our situation, after digestion by restriction endonuclease EcoRI, the total BY2 genomic DNA $(50 \mu \mathrm{g})$ was separated in a $0.7 \%(\mathrm{w} / \mathrm{v})$ agarose gel in $0.5 \times \mathrm{TBE}$ without ethidium bromide and transferred onto a blotting membrane (Millipore corporation, Billerica, $\mathrm{MA}$ ). Then the membrane was hybridized with the DIGtagged DNA probes synthesized by PCR. Hybridizations were carried out at $42^{\circ} \mathrm{C}$. Two rounds of low stringency membrane wash and four rounds of high stringency wash were performed due to the very high BY2 genomic DNA background ( $50 \mu \mathrm{g}$ BY2 genomic DNA each sample), and the hybridization signal detection was carried out according to the detection kit manufacturer's instructions (DIG-High Prime DNA labelling and detection starter kit II, Roche).

\section{Analysis of GFP Gene Expression by Fluorescence Microscopy \\ Fluorescence microscopy was performed using Leica} DM2500 fluorescence microscope and DFC420 C camera (Leica, Germany) with the GFP excitation and emission module.

\section{Analysis of GFP Gene Expression by Semi-quantitative $R T-P C R$ \\ Total RNA was extracted from callus according to} Verwoerd et al. (1989), with adding carborundum to help grinding. The extracted total RNA was treated by RNasefree DNase I (Takara, Japan). Then the treated RNA was used as template for reverse transcription (RT) reaction according to the manufacturer's instructions of the M-MLV 
First strand kit (Invitrogen). The resulted complementary DNA (cDNA) was diluted 10 to 20 folds and then used as the template for PCR reaction. PCR primers for GFP gene were PGF (5'-ATGGTGAGCAAGGGCGAGGA-3'), PGR (5'-TTACTTGTACAGCTCGTCCA-3'). In all RT-PCR reactions, the tobacco UBIQUITINI (NtUBQ1) gene was used as the internal control for input cDNA amount normalization. To get rid of the interference of residual genomic DNA, the CDNA of no promoter: GFP, i.e. BY2 transformed by pGWB4 (Invitrogen) construct, was used as the non-RT control.

\section{Results}

An optimized BY2 Agrobacterium-mediated transformation protocolwas established

When BY2 was transformed according to the traditional procedure (Menges and Murray, 2006), even after three weeks of post-transformation incubation on the selective plates, the cells seemed to have never recovered from the initial growth stasis, which was caused by Agrobacterium infection, and exhibited little proliferation. We checked the cells by Evans Blue staining at the end of incubation and found almost all cells (above 85\%) was unviable in the groups treated by ditional method (Fig. 1C$\mathrm{E}$ and I). Notably, even on non-selective plate, the transformed cells dispersed by the traditional method also failed in proliferating, suggesting it was not Agrobacterium treatment that caused the cell growth failure. However, only a few of cell death (below 15\%) occurred in groups treated by modified method (Fig. 1F- I). Comparison between the cells whose proliferation could and could not be efficiently initiated exhibited that the former were exposed in the air
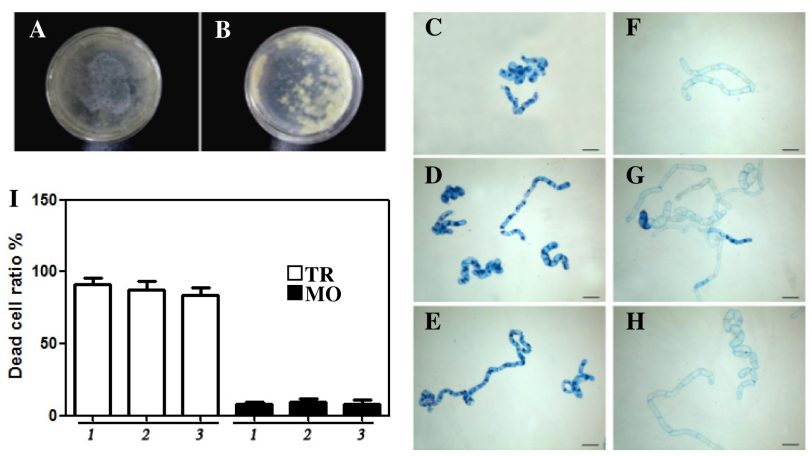

Fig. 1. Cell proliferation and growth compare between traditional and modified mean

(A) 2 weeks-past cells grow slowly and difficultly on plating with lower cell density. (B) 2 weeks-past cells grow and form callus rapidly on plating with higher cell density $(2 \times$ folds cell density of TR). (C), (D) and (E) Cells treated by traditional mean, were stained with Evans Blue. (F), (G) and (H) Cells treated by modified method, were stained with Evans Blue. (I) Percentage of cell death shown in traditional method (TR) and modified method (MO) ( $>30$ microscope view areas; $\mathrm{p}<0.05$, Student's t test) 1,2 and 3 means 3 independent transgenic groups. Bar $=10 \mu \mathrm{m}$ during the post-transformation incubation, while the later were soaked in the liquid medium, which was added at the aliquot step to easily disperse the cell on the selective plate. This excess of liquid medium remained at almost all the time of the incubation. Thus we tried to get rid of excess liquid medium covering the cell pellet before cell dispersion, and found that cell growth could be initiated rapidly.

Meanwhile we noticed that the cells in some plates with occasional higher cell density could quickly recover from Agrobacterium infection and initiate proliferation more efficiently than those with lower cell density (Fig. 1A and B). We tested several cell density gradients as $1 \times 10^{6}, 1.5 \times 10^{6}$, $2 \times 10^{6}$ and $3 \times 10^{6}$ cells $/ \mathrm{ml}$ in the trasformation protocol, and found $2 \times$ folds (Fig. 1B) and $3 \times$ folds of traditional density worked the best for recovery from Agrobacterium infection. If transformation is unsuccessful, the cell density should be optimized to reach at least $2 \times 10^{6}$ cells $/ \mathrm{ml}$. Meanwhile the original $9 \mathrm{~mm}$ diameter plates were replaced by $5 \mathrm{~mm}$ diameter plates, and the round number of the washing step was changed to one time instead of original three times to save more cells for aliquot.

With all above improvements adopted, separated individual transformed callus could be visible by naked eyes in approximately two weeks after final plating the cells (Fig. 2BD). Then the new calluses were transferred onto freshly prepared antibiotics plates 3 weeks after aliquot (Fig. 2F-H). The contamination of non-transformed calluses would be inhibited effectively during subculture under selective pressure. Compared with the non-transformant controls
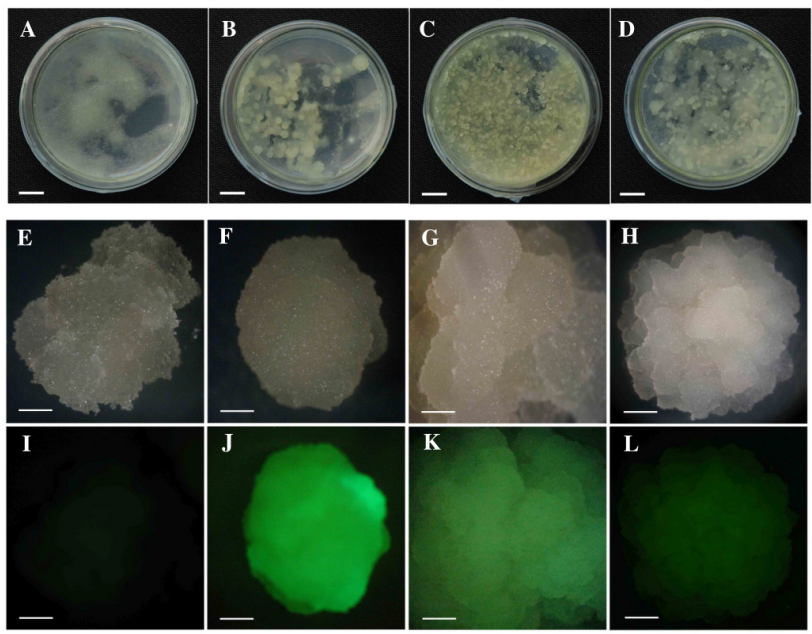

Fig. 2. Calluses of transformed and wild type BY2 cells growing on selective medium

(A), (E) and (I) non-transformed cell cultivated on MS medium. (B), (F) and (J) 35S:GFP transformed callus on selective medium. (C), (G) and (K) AtUBQ10:GFP transformed callus on antibiotic medium. (D), (H) and (L) AtASK1: GFP transformed callus on antibiotic medium. (E) and $(\mathrm{I}),(\mathrm{F})$ and $(\mathrm{J}),(\mathrm{G})$ and $(\mathrm{K}),(\mathrm{H})$ and $(\mathrm{L})$ the same views correspondingly, taken by bright field and fluorescence microscopy modules, respectively. Bar $=1 \mathrm{~cm}$ in $\mathrm{A}-\mathrm{D}$ and Bar $=0.5 \mathrm{~mm}$ in E-L 
475

(Fig. 2A, E and I), in the transformed calluses with integrated GFP expression construct, green fluorescence respectively driven by CaMV35S, AtUBQ10 and AtASK1 promoters could be clearly observed (Fig. 2J-L).

DNA gel blot assay (Southern assay) verified that stable transformed calluses were obtained

Tobacco (Nicotiana tabacum) possesses a tremendous large genome with approximately 4.8 billion base pairs overall length, so that huge amount of input of genomic DNA is required for single copy target sequence detection within the whole genome. However, the traditional plant genomic DNA extraction protocol can hardly accomplish sufficient recovery of BY2 genomic DNA (Fig. 3C). We had used DAPI staining to check the homogenized product prepared by the conventional method and found a lot of nuclei had not been broken at all so that the recovery ratio of genomic DNA was very low (Fig. 3A and B). Freeze drying the cell pellet before grinding it in mortars. The resulted stuff was much easier to be ground to powder (Foitova and Kovarik, 2000), and the breakage ratio of the nuclei was almost $100 \%$, and approximately $0.5-0.6 \mathrm{mg}$ BY2 genomic DNA could be recovered from $100 \mathrm{ml} 10$-day liquid medium culture inoculated from a single callus (Tab. 1).

The Southern assay demonstrated that majority of transformed calluses harbored two copies of integrated transgenes within tobacco genome (Fig. 4). Furthermore, as
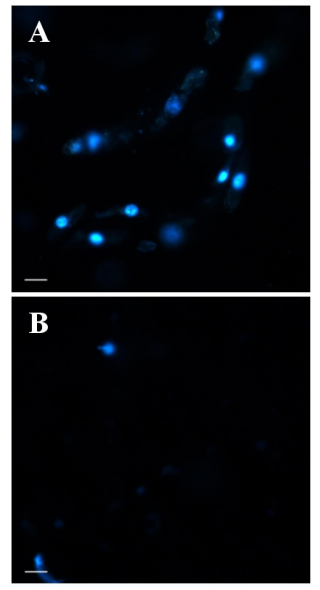

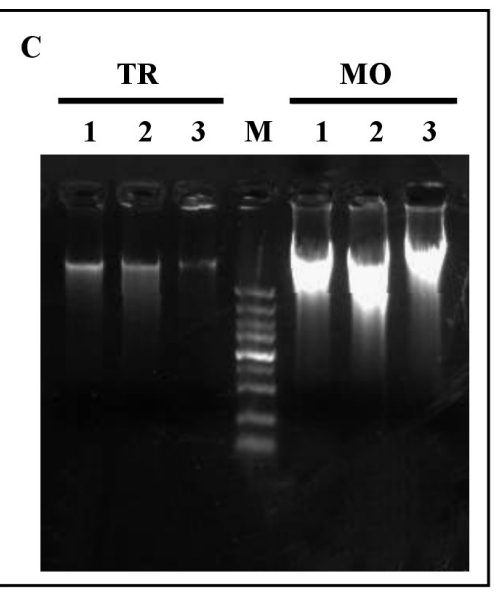

Fig. 3. Total DNA extraction by different methods

(A) and (B) DAPI stained nuclei of cells broken by traditional and modified methods. (C) Detection of total genomic DNA extraction by traditional and modified processing, line 1, 2, 3 are independent sample loaded with $5 \mu \mathrm{l}$, TR mean traditional method, MO mean modified method. Bar $=10 \mu \mathrm{m}$.

for the transformed calluses harboring multiple copies of transgenes, we found the hybridization intensity of the target bands were always the same, as soon as the callus was transferred to a fresh selective plate no later than 3 weeks.

Transgene could be stably expressed at least for 20 days in liquid culture

The GFP fluorescence expression driven by CaMV $35 S$ promoter $(35 S: G F P)$ in transformed BY-2 cells, which came from genetically uniform callus, was displayed in Fig. 2B. In most of transformed BY2, GFP fluorescence could be detected for at least 3 cycles of -liquid medium subculture, approximately 20 days (Fig. 5A). According to our observation of cell proliferation rate in liquid medium, approximately 16 generations of cell proliferation were committed during such duration. Notably, we found from the 10th day to the 20th day after inoculation in liquid culture, little difference could be detected in the ratio of GFP fluorescence of the culture under selective pressure compared with those dismissed from selective pressure, i.e. with no antibiotics added (Fig. 5A). The result of semiquantitative RT-PCR also verified that in later subculture, after 10 days of inoculation in liquid culture, until as late as the 20th days, there was no significant difference between the cultures under selective pressure and non-selective (Fig. $5 B)$.

Tab 1. Comparation between traditional and modified processing of Total DNA extraction

\begin{tabular}{ccccc}
\hline Group & $\begin{array}{c}\text { Fresh- } \\
\text { weight of } \\
\text { sample }(\mathrm{g})\end{array}$ & $\begin{array}{c}\text { Total } \\
\text { DNA } \\
(\mu \mathrm{g})\end{array}$ & $\begin{array}{c}\text { Extraction } \\
\text { efficience } \\
(\mu \mathrm{g} / \mathrm{g})\end{array}$ & $\begin{array}{c}\text { Mean } \\
(\mu \mathrm{g} / \mathrm{g})\end{array}$ \\
\hline \multirow{3}{*}{$\begin{array}{c}\text { Traditional } \\
\text { method }\end{array}$} & 40.51 & 5.83 & 0.14 & \\
& 47.23 & 5.19 & 0.11 & \\
& 39.16 & 2.74 & 0.07 & 0.14 \\
& 43.52 & 9.13 & 0.21 & \\
Modified & 44.24 & 7.52 & 0.17 & \\
method & 42.17 & 304.81 & 7.23 & \\
& 45.55 & 310.25 & 6.81 & \\
& 46.05 & 320.86 & 6.97 & 6.9 \\
\hline
\end{tabular}

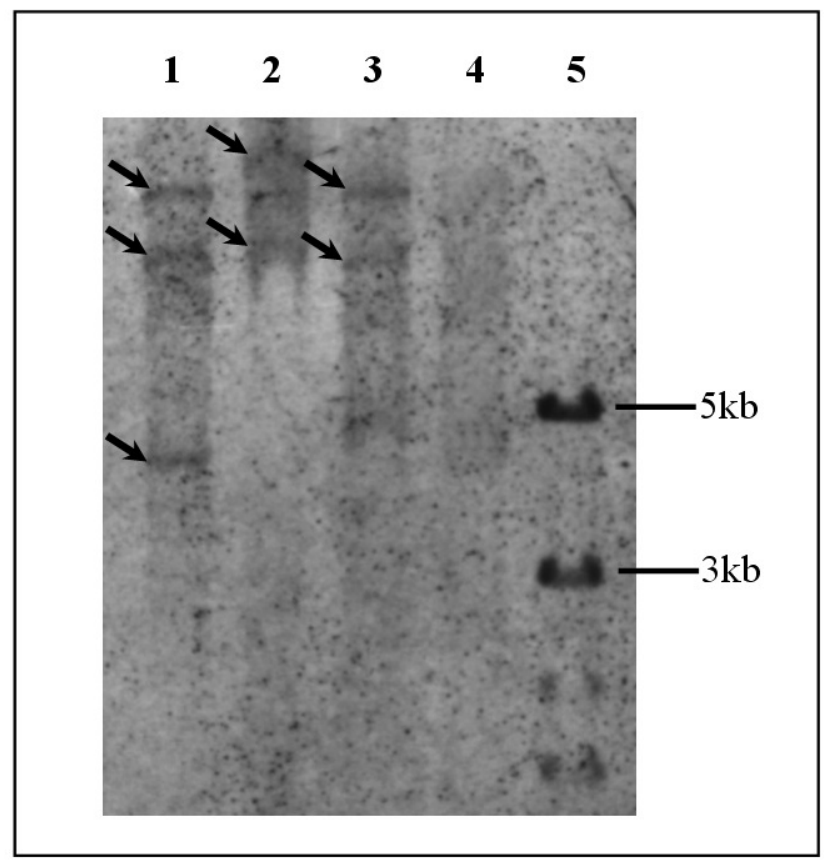

Fig. 4. Estimation of transgene copy number by Southern hybridization

Lane 1 to 3, independent GFP transgenic calluses. Lane 4, nontransformed BY2 control. Lane 5, molecule weight marker. Arrows indicate the integrated transgenes containing GFP sequence were probed 


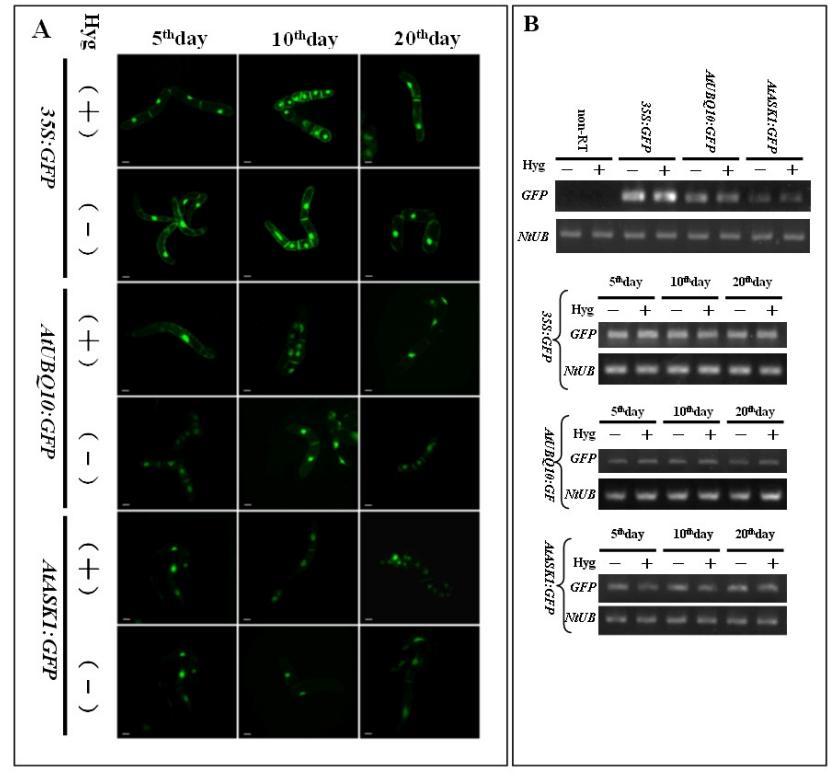

Fig. 5. GFP expression in different transgenic BY2 cells

(A) Detection of GFP expression under fluorescence microscope. GFP expression driven by $35 S$, AtUBQ10 and AtASK1 shown in the BY2 cell cultivated in liquid medium with or without hygromycin (labeled with $(+)$ and $(-)$, respectively) for 5, 10 and 20 days. Bar $=10 \mu \mathrm{m}$.

(B) Semi-quantitative RT-PCR to quantify GFP expression in the 35S:GFP, AtUBQ10:GFP and AtASK1:GFP transformed cells, respectively. Tobacco UBIQUITIN 1 (NtUBQ1) was used as the internal control for total cDNA amount normalization. No promoter: GFP was used as the non-RT control. Three independent replicates performed and one representative result illustrated. At least 15 independent calluses all with two copies of transgene integrated for each type transgenic BY2 were used to perform the experiment

Meanwhile GFP genes, whose expression were driven by AtUBQ10 (AtUBQ10:GFP) and AtASK1 (AtASK1:GFP) promoters were introduced into BY2 in parallel with 35S:GFP construct. Representative features of the cells transformed with AtUBQ10:GFP, AtASK1:GFP and 35S:GFP, respectively, are illustrated in Fig. 5. In the prerequisite of harboring the same copy number (here was two) of transgene, the AtUBQ10 promoting strength was estimated about $50 \%$ of CaMV $35 S$ promoter, and AtASK1 promoting strength was about $20-30 \%$ of $35 S$ promoter according to fluorescence strength (Fig. 5A), which was further verified by semi-quantitative RT-PCR (Fig. 5B). Thus, it suggested that CaMV 35S, AtUBQ10and AtASK1 can drive GFP to be expressed in vivo no matter when BY2 is at proliferative stage (exponential stage) or stationary growth stage with less mitosis. The BY2 cell suspension is a good platform to test the potentials of constitutive promoters in plant.

\section{Discussion}

In the traditional protocol, the final aliquot requires $2 \mathrm{ml}$ liquid medium to disperse the cell pellet transformed by
Agrobacterium (David and Perrot-Rechenmann, 2001). However, we found the excess liquid medium which was covering the transformed cell during incubation, had impeded severely aerobic respiration of the cells. Meanwhile, the excess liquid medium enforced mobility of the cell such that it was more difficult for the cell to anchor the solid medium and initiate proliferation. According to our experience, almost all aliquots failed to initiate growth with over $0.5 \mathrm{ml}$ liquid medium during the longtime incubation. So an extra centrifuge step was added in the final aliquot step to discard excess liquid medium, i.e. at most $0.5 \mathrm{ml}$, rather than original $2 \mathrm{ml}$ liquid medium was left for dispersing the cell pellet.

Genetically uniform calluses are ideal for testing the effects of growth factors or stress substances on cell growth. However, according to the traditional protocol antibiotics were kept in the transformed cell suspension during all subsequent subcultures, and the strong adverse effects of antibiotics made the cell grow unhealthy and influenced precise evaluation of effects of growth factors or stress substances. To get rid of such problem, we set up samples of antibiotics-added and no-antibiotics-added. We found in next round of liquid subculture (10 to 20 days after inoculation) no significant difference of transgene abundance could be detected between antibitocis-added and nonantibiotics-added samples (Fig. 5B). That means antibiotics can be dismissed for subculture of transformed callus, only if the initial callus has been well segregated and definitely genotyped. However, caution should be taken to extend our observance to other cases of transgenes, because up to date we have not found any cases that transgenes affect the callus grow significantly compared with non-transformed callus, i.e. even trace of non-transformed cell proliferates, it does not constitute severe problem of genetic impurity during subculture.

Meanwhile we found that the transgenes are stably expressed for at least 20 days in liquid subculture. If it was a little obscure that GFP fluorescence was viewed for evaluation of the expression level of transgene, the semiquantitative PCR unambiguously exhibited that transgenes are stably expressed. According to the intensity of the fluorescence, the relative potentials of promoters could be estimated and quantified, with assistance of semi-quantitative RT-PCR, in prerequisite of harboring the same copy number of the transgene that was demonstrated by the optimized Southern blot. This advantage would be especially useful to exploit more constitutive promoters in plant, and study ciselements of important signaling pathways. Thus we believed that our optimized protocol has provided a uniform and highly replicable experimental cellular platform to investigate many aspects of plant cell biology.

\section{Acknowledgements}

We thank Huang Hai laboratory for providing the original BY2 strain, pCAMBIA1300GR vector and precious technique support for BY2 culture and transformation. The excellent technical assistance of Fei W, Fan F and Wufei Q is highly appreciated. This work was supported by the National Natural Science Foundation of China (30870225). 


\section{References}

Aidemark M, Tjellström H, Sandelius AS, Stålbrand H, Andreasson E, Rasmusson AG, Widell S (2010). Trichoderma viride celluase induces resistance to the antibiotic pore-forming peptide alamethicin associated with changes in the plasma memvrane lipid composition of tobacco BY-2 cells. BMC Plant Biol 10:1-13.

Cogoni C, Macino G (1999). Homology-dependent gene silencing in plant and fungi: a number of variations on the same theme. Curr Opin Microbiol 2:657-662.

Chen R, Zhao X, Shao Z, Wei Z, Wang Y, Zhu L, Zhao J, Sun M, He $\mathrm{R}, \mathrm{He}$ G (2007). Rice UDP-glucose pyrophosphorylase 1 is essential for pollen callose deposition and its cosupperssion results in a new type of thermosensitive genic male sterility. Plant Cell 19:847-861.

Cornejo MJ, Luth D, Blankenship KM, Anderson OD, Blechi AE (1993). Activity of a maize ubiquitin promoter in transgenic rice. Plant Mol Biol 23:567-581.

David KM, Perrot-Rechenmann C (2001). Characterization of a tobacco 'Bright Yellow 2' cell line expressing the tetracycline repressor at a high level for strict regulation of transgene expression. Plant Physiol 125:1548-1553.

Duby G, Degand H, Faber AM, Boutry M (2010). The proteome complement of Nicotiana tabacum 'Bright Yellow 2' culture cells. Proteomics 10:2545-2550.

Fojtova M, Kovarik A (2000). Genotoxic effect of cadmium is associated with apoptotic changes in tobacco cells. Plant Cell Environ 23: 531-537.

Grefen C, Donald N, Hashimoto K, Kudla J, Schumacher K, Blatt MR (2010). A ubiquitin-10 promoter-based vector set for fluorescent protein tagging facilitates temporal stability and native protein distribution in transient and stable expression studies. Plant J 64:355-365.

Ito M, Marie-Claire C, Sakabe M, Ohno T, Hata S, Kouchi H, Hashimoto J, Fukuda H, Komamine A, Watanabe A (1997). Cell-cycle-regulated transcription of A- and B-type plant cyclin genes in synchronous cultures. Plant J 11:983-992.

Link BM, Cosgrove DJ (1998). Acid-growth response and alphaexpansins in suspension cultures of 'Bright Yellow 2' tobacco. Plant Physiol 188:907-916.

Liu F, Ni W, Griffith ME, Huang Z, Chang C, Peng W, Ma H, Xie D (2004). The ASK1 and ASK2 genes are essential for Arabidopsis early development. Plant Cell 16:5-20.

Lutz KA, Wang W, Zdepski A, Michael TP (2011). Isolation and analysis of high quality nuclear DNA with reduced organellar DNA for plant genome sequencing and resequencing. BMC Biotechnol 11:54-61.

Menges M, Murray JA (2006). Synchronization, transformation, and cryopreservation of suspension-cultured cells. Methods Mol Biol 323:45-61.

Miao Y, Jiang L (2007). Transient expression of fluorescent fusion proteins in protoplasts of suspension cultured cells. Nat Protoc 2:2348-2353.
Nagata T, Nemoto Y, Hasezawa S (1992). Tobacco BY2 cell line as the 'Hela' cell in the cell biology of higher plants. Int Rev Cytol 132:1-30.

Nakayama H, Yoshida K, Ono H, Murooka Y, Shinmyo A (2000). Ectoine, the compatible solute of Halomonas elongate, confers hyperosmotic tolerance in cultured tobacco cells. Plant Physiol 122:1239-1247.

Nizampatnam NR, Doodhi H, Kalinati Narasimhan Y, Mulpuri S, Viswanathaswamy DK (2009). Expression of sunflower cytoplasmic male sterility-associated open reading frame, orfH522 induces male sterility in transgenic tobacco plants. Planta 229:987-1001.

Saghai-Maroof MA, Soliman KM, Jorgensen RA, Allard RW (1984). Ribosomal DNA spacer -length polymorphisms in barley: mendelian inheritance, chromosomal location, and population dynamics. Proc Natl Acad Sci USA 81:8014-8018.

Sambrook J, Russell DW (2001). Molecular Cloning: A Laboratory Manual. 3rd Ed. Cold Spring Harbor Lab Press, New York, 183 p.

Sparkes IA, Runions J, Kearns A, Hawes C (2006). Rapid, transient expression of fluorescent fusion proteins in tobacco plants and generation of stably transformed plants. Nat Protoc 1:2019-2025.

Sullivan JA, Shirasu K, Deng XW (2003). The diverse roles of ubiquitin and the $26 \mathrm{~S}$ proteasome in the life of plants. Nat Rev Genet 4:948-958.

Teixeira RT, Farbos I, Glimelius K (2005). Expression levels of meristem identity and homeotic genes are modified by nuclearmitochondrial interactions in alloplasmic male-sterile lines of Brassica napus. Plant J 42:731-742.

Vaucheret H, Beclin C, Elmayan T, Feuerbach F, Godon C, Morel JB, Mourrain P, Palaugui JC, Vernhettes S (1998). Transgeneinduced gene silencing in plant. Plant J 16:651-659.

Verwoerd TC, Dekker BM, Hoekema A (1989). A small-scale procedure for the rapid isolation of plant RNAs. Nucleic Acids Res 17:2362.

Wang YX, Wu H, Liang GQ, Yang M (2004). Defects in nucleolar migration and synapsis in male prophase I in the ask 1-1 mutant of Arabidopsis. Sex Plant Reprod 16(6):273-282.

Yang M, Hu Y, Lodhi M, McCombie WR, Ma H (1999). The Arabidopsis SKP1-LIKE1 gene is essential for male meiosis and may control homologue separation. Proc Natl Acad Sci USA 96:11416-11421.

Zhang Q, Huang L, Liu T, Yu X, Cao J (2008). Functional analysis of a pollen-expressed polygalacturonase gene $B c M F 6$ in Chinese cabbage (Brassica campestris L. ssp. chinensis Makino). Plant Cell Reports 27(7):1207-1215.

Zheng N, Schulman BA, Song L, Miller JJ, Jeffrey PD, Wang P, Chu C, Koepp DM, Elledge SJ, Pagano M, Conaway RC, Conaway JW, Harper JW, Pavletich NP (2002). Structure of the Cul1-Rbx1-Skp1-F boxSkp2 SCF ubiquitin ligase complex. Nature 416:703-709. 